This is an electronic reprint of the original article. This reprint may differ from the original in pagination and typographic detail.

Author(s): Järvinen, Joel; Taiminen, Heini

Title: Harnessing marketing automation for B2B content marketing

Year: $\quad 2016$

Version:

Please cite the original version:

Järvinen, J., \& Taiminen, H. (2016). Harnessing marketing automation for B2B content marketing. Industrial Marketing Management, 54, 164-175. https://doi.org/10.1016/j.indmarman.2015.07.002

All material supplied via JYX is protected by copyright and other intellectual property rights, and duplication or sale of all or part of any of the repository collections is not permitted, except that material may be duplicated by you for your research use or educational purposes in electronic or print form. You must obtain permission for any other use. Electronic or print copies may not be offered, whether for sale or otherwise to anyone who is not an authorised user. 


\title{
Harnessing marketing automation for B2B content marketing
}

\begin{abstract}
The growing importance of the Internet to B2B customer purchasing decisions has motivated B2B sellers to create digital content that leads potential buyers to interact with their company. This trend has engendered a new paradigm referred to as 'content marketing.' This study investigates the organizational processes for developing valuable and timely content to meet customer needs and for integrating content marketing with B2B selling processes. The results of this single case study demonstrate the use of marketing automation to generate high-quality sales leads through behavioral targeting and content personalization. The study advances understanding of the organizational processes that support content marketing and shows how content marketing can be combined with B2B selling processes via marketing automation in ways that achieve business benefits.
\end{abstract}

Keywords: case study, digital marketing, marketing and sales alignment, new technologies, sales funnel, social media 


\section{Introduction}

Recent advances in communications and information technology (IT), and the rise of digital content and social media in particular, are transforming the ways in which individuals and businesses search for information and interact with one another (Dennis, Merrilees, Jayawardhena, \& Wright, 2009; Greenberg, 2010; Kietzmann, Hermkens, McCarthy, \& Silvestre, 2011). A fundamental shift in the B2B sector involves the growing influence of digital communication channels in customer purchasing decisions (Lingqvist, Plotkin, \& Stanley, 2015; Wiersema, 2013). A Corporate Executive Board study of more than 1,400 B2B buyers found that customers rely heavily on online information sources and complete nearly $60 \%$ of a typical purchasing process before contacting a seller (Adamson, Dixon, \& Toman, 2012). This active role played by B2B buyers in searching for and evaluating information online has given rise to a new marketing paradigm referred to as '(digital) content marketing.'

In this study, the term 'content' refers to all forms of digital content. We employ the definition of content marketing presented by Holliman and Rowley (2014, p. 285), who tailored the concept to the B2B context as follows: "B2B digital content marketing involves creating, distributing and sharing relevant, compelling and timely content to engage customers at the appropriate point in their buying consideration processes, such that it encourages them to convert to a business building outcome." This definition highlights the role of content marketing as an inbound marketing (i.e., pull marketing) tactic directed at generating valuable content based on the needs of potential buyers who have already searched for information on a product or service (Halligan \& Shah, 2010). 
The use of content marketing is becoming widespread in the B2B sector. According to a recent survey, as many as $86 \%$ of $\mathrm{B} 2 \mathrm{~B}$ marketers $(\mathrm{n}=1820)$ in North America use content marketing tactics as a strategic marketing approach, and $47 \%$ have a dedicated content marketing group in their organization (Pulizzi \& Handley, 2014). However, existing knowledge on B2B content marketing is largely based on research reports produced by commercial research institutions (e.g., Content Marketing Institute, eMarketer, Marketing Profs), and academic research on the subject remains in its infancy. One exception is a study conducted by Holliman and Rowley (2014), who interview 15 B2B content marketers from various industries and offer a number of insights into best practices and the challenges of content marketing in the B2B sector. The present study employs a more focused approach, as it concentrates on the organizational processes that support content marketing and their relation to B2B sales. Indeed, the relationship between digital marketing and B2B sales has attracted very limited attention in the existing literature (Pomirleanu, Schibrowsky, Peltier, \& Nill, 2013; Rodriguez, Dixon, \& Peltier, 2014).

Understanding the role of content marketing in B2B sales is particularly crucial given persistent conflicts between marketing and sales departments with regards to lead generation and management. Sales representatives criticize the quality of marketing leads, and marketers criticize sales representatives' poor follow-up skills (e.g., Biemans, Brencic, \& Malshe, 2010; Homburg \& Jensen, 2007; Homburg, Jensen, \& Krohmer, 2008). Insufficient lead follow-up is indeed a serious issue in the B2B sector, and one study has shown that sales representatives ignore approximately $70 \%$ of all leads generated via marketing (Marcus, 2002). Clearly, if the majority of marketing leads are never contacted and instead disappear into the notorious 'sales 
lead black hole' (see, e.g., Hasselwander, 2006; Sabnis, Chatterjee, Grewal, \& Lilien, 2013), content marketing efforts toward producing sales will prove fruitless.

IT developments present opportunities for fostering cooperation and strengthening the interfaces between (content) marketing and B2B selling processes. Wiersema (2013) argues that by integrating marketing and sales systems, marketing teams could acquire deeper insight into the customer data in customer relationship management systems (CRM), and sales teams could in turn learn more about activities and leads generated through marketing efforts. The integration of marketing and sales systems is essential, as sales departments often employ their own sales management tools, from which marketing departments are deliberately excluded (Kotler, Rackham, \& Krishnaswamy, 2006).

One IT tool that is attracting increasing attention in the B2B sector is marketing automation. Vendors of the software (e.g., Eloqua, Hubspot, Marketo, Pardot, Silverpop) claim that the tool allows companies to align marketing and sales system interfaces to improve and accelerate lead qualification processes via 'lead scoring and nurturing,' thus targeting potential buyers through the use of personalized content. Assuming that the vendors deliver on these promises, B2B companies may be able to use marketing automation tools to deliver more effective content marketing strategies and thereby improve lead follow-up practices. From interviews with 72 executives and 30 B2B researchers, Wiersema (2013) finds that one of the key developments in the B2B sector lies in the technological automation of manual tasks performed by marketers. To our knowledge, however, no academic study has yet investigated the benefits of combining content marketing and marketing automation technological tools. 
Based on this context, this study achieves three objectives. First, it advances knowledge on the organizational processes of B2B content marketing in terms of creating and delivering timely and valuable content based on customer needs. Second, the study examines ways in which content marketing strategies may be combined with B2B selling processes via marketing automation and the benefits and challenges of such an approach. Third, the study contributes to ongoing discussions on marketing and sales alignment in the B2B sector by illustrating ways in which marketing and sales systems may be integrated through advancements in IT.

To achieve these study objectives, we perform an in-depth investigation of an industrial company that has benefitted considerably from content marketing and marketing automation integration. More specifically, we exploit the sales funnel conceptualization (see the definition presented in section 2.2) outlined by D'Haen and Van den Poel (2013) as our guiding framework and explain how the case company capitalizes on content marketing and marketing automation techniques to support sales processes at each funnel phase.

The remainder of this article is organized as follows. We begin by elaborating on concepts of content marketing and marketing automation. We then elaborate on the sales funnel framework and describe the potential role that content marketing and IT tools may play in this framework. In the section on methodology, we justify our use of a single case study and describe the data collection and analysis methods employed. We then present the study findings. We conclude with a discussion of the study's theoretical contributions, managerial implications, and research quality, and present avenues for future research. 


\section{Integrating content marketing tactics with B2B selling processes}

\subsection{Content marketing and marketing automation}

Although content marketing can employ content in traditional formats (e.g., customer magazines and brochures), the digital environment has popularized the term: 'content marketing' for many authors refers purely to content in digital formats (Handley \& Chapman, 2011; Rose \& Pulizzi, 2011: Wuebben, 2011). According to Chaffey and Smith (2013), the most commonly used formats of digital content include pictures, videos and animations, e-books or shorter customer guides, white papers, podcasts, webinars, infographics, blog texts and social media posts. The primary business objectives of B2B content marketing are related to promoting brand awareness and image, fostering customer engagement, and increasing sales through customer acquisitions, lead generation, upselling and cross-selling (Holliman \& Rowley, 2014; Pulizzi \& Handley, 2014).

Content marketing is closely related to social media marketing; their business objectives are largely aligned and the notion of storytelling rather than promotional communications is central to both concepts (see, e.g., Christodoulides, 2009; Fournier \& Avery, 2011; Hennig-Thurau et al., 2010; Michaelidou, Siamagka, \& Christodoulides, 2011; Rose \& Pulizzi, 2011; Singh \& Sonneburg, 2012). Moreover, content marketing is a technique or approach employed in social media environments (Pulizzi, 2011). In this sense, social media can be understood as a set of channels and platforms to deliver and share content.

Marketing automation involves a software platform that can be used to deliver content based on specific rules set by users. The objective is to attract, build and maintain trust with current and 
prospective customers by automatically personalizing relevant and useful content to meet their specific needs (Kantrowitz, 2014; Hubspot, 2015). The term personalization generally refers to the customization of marketing mix elements (e.g., content personalization) at an individual scale (Montgomery \& Smith, 2009). The goal is to treat a person as a maverick with individualistic needs and to design content to meet his or her expectations. According to the elaboration likelihood model (ELM), the more personal and relevant a message is, the more likely that the message will be noticed, thus increasing its effectiveness (Petty \& Cacioppio, 1986).

Marketing automation capitalizes on techniques similar to Web analytics (see, e.g., Järvinen \& Karjaluoto, 2015; Phippen, Sheppard, \& Furnell, 2004; Wilson, 2010) by tracking website visitors' online behaviors (i.e., navigation paths and page views) through the use of cookies and IP addresses. The two tools differ in that marketing automation employs advanced capabilities for identifying individual customers and following their behaviors over extended periods of time, and these functions are typically limited in Web analytics software tools such as Google Analytics. Notably, tracking individual behaviors over time requires that a visitor first identifies him or herself by completing a website contact form.

Marketing automation exploits both active and passive means of learning about potential buyers. Active approaches involve directly asking questions, and passive approaches involve utilizing information on past transactions or clickstream data (Montgomery \& Srinivasan, 2003). In the marketing automation context, active approaches refer to content delivered to customers that includes links to websites associated with questions (e.g., 'would you like to learn more about this topic?' or 'would you like our sales representatives to contact you?'). Based on these active 
and passive tools, a software program can personalize messages and detect the buying stage a potential customer is engaged in (Kantrowitz, 2014). To summarize, while content marketing and marketing automation tactics offer promising opportunities for B2B sales, very little is known regarding how $\mathrm{B} 2 \mathrm{~B}$ companies can harness these tools to guide potential buyers engaged in different stages of the B2B sales process.

\subsection{Content marketing and marketing automation within the sales funnel framework}

The sales funnel framework illustrates the sequential narrowing of a firm's customer base from all potential customers who may be interested in a firm's products and services to those "closed" customers who actually make a purchase (Cooper \& Budd, 2007; Dalrymple, Cron, \& DeCarlo, 2004). In other words, the sales funnel categorizes potential customers based on their purchasing stage. Although the sales funnel conceptualization is widely recognized in business and academia, its exact form and the number and order of stages vary from study to study.

The sales funnel framework employed in this study is adapted from D'Haen and Van den Poel (2013), who divide the sales funnel into the following categories: suspects, prospects, leads and customers (Figure 1). However, the sales funnel outlined by D'Haen and Van den Poel is purely designed for customer acquisition and therefore ends when a lead is converted to customer, while our vision of the funnel also includes existing customers who serve as potential targets for repurchasing, upselling and cross-selling. In this sense, we view the sales funnel as a loop that existing customers can re-enter. Because existing customers can occupy any stage of the funnel, we have replaced the final stage 'customers' with 'deals,' as suggested by Patterson (2007). In the following section, we describe the phases of the sales funnel in greater detail and discuss the roles of content marketing and IT in each phase. 


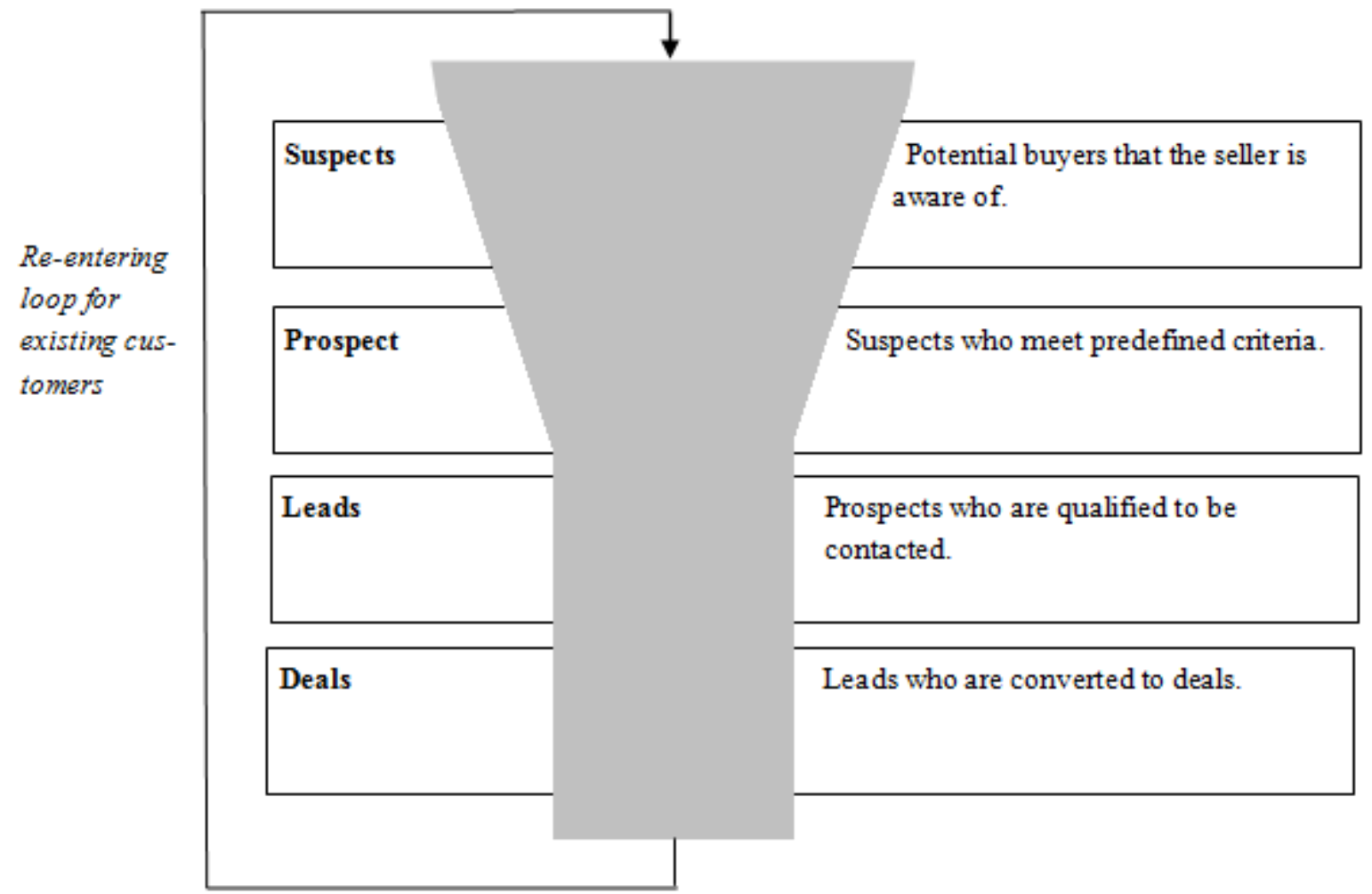

Figure 1: Sales funnel framework (adapted from D’Haen \& Van den Poel, 2013)

\subsubsection{From suspects to prospects}

Suspects include all potential buyers that the seller is aware of (D’Haen \& Van den Poel, 2013). While the pool of potential buyers can theoretically be very large, its size is typically limited by the firm resources available to search for potential buyers and by investments in "cold call lists" purchased from specialized vendors (Buttle, 2009; Rygielski, Wang, \& Yen, 2002; Wilson, 2006). Excessively expanding the pool of suspects may be counterproductive, as this complicates the task of screening and selecting prospects (i.e., suspects who meet predefined criteria). Indeed, prospect selection is considered to be the most arduous task of the selling process and requires substantial human resources (Moncrief \& Marshall, 2005; Trailer \& Dickie, 2006). Therefore, B2B sellers are likely to benefit from focusing on suspect quality over suspect quantity. 
Content marketing can serve as an effective means for B2B sellers to improve suspect quality, as the Internet is frequently used by B2B buyers as an initial source of information during the early stages of their purchase process (Wiersema, 2013). According to Long, Tellefsen and Lichtenthal (2007), digital environments offer ample opportunities for B2B sellers to attract potential buyers to company websites and motivate them to identify themselves. Clearly, creating and delivering compelling and relevant content to target audiences across digital media provides sellers with a particularly promising opportunity to attract suspects to a company website (Holliman \& Rowley, 2014; Wolk \& Theysohn, 2007). Suspects can thereby be motivated to identify themselves to allow access to desired content (e.g., white papers, research reports, webinars). Suspects acquired through content marketing are presumably more likely to qualify as prospects relative to suspects acquired through other methods, as the consumption of content targeted to potential customers signifies that a suspect at least has an initial interest in the company.

\subsubsection{From prospects to leads}

Prospect selection is followed by lead qualification. In lead qualification, the seller aims to identify those prospects that offer the highest probability of profitable sales (Long et al., 2007). If sales representatives work at full capacity, sales efficiency can only be increased by contacting more top-ranked prospects (D’Haen \& Van den Poel, 2013). However, objectively determining which prospects are most likely to convert to deals has proven to be extremely challenging in the realm of B2B sales. In practice, lead qualification is often based on intuition and self-proclaimed competence (Jolson, 1988), and sales representatives often employ heuristic rules (e.g., rules of thumb, educated guesses) to qualify leads (D'Haen \& Van den Poel, 2013). Errors in the lead 
qualification process result in wasted resources and losses in sales revenue when sales representatives fail to focus on the most profitable leads (Monat, 2011).

The challenges in lead qualification stem from two issues. First, there is no consensus regarding the characteristics of a high-quality lead, as such features may vary from company to company (Monat, 2011). In general, the lead characteristics considered to be crucial include the prospect's source (e.g., direct mail, advertising, telemarketing, website or tradeshow (Jolson, 1988)), the prospect's need and degree of urgency (Donath, 1999; Donath, Crocker, Dixon, \& Obermayer, 1995; Jolson, 1988; Jolson \& Wotruba, 1992), the prospect's funds and authority over decisions (Donath, 1999; Donath et al., 1995; Jolson, 1988; Jolson \& Wotruba, 1992), the prospect's willingness to provide information (Jolson, 1988; Jolson \& Wotruba, 1992; Monat, 2011), whether the lead was initiated by the company or by the prospect (Jolson, 1988), and whether the prospect has conducted business with the seller before and/or fits the profile of a key account (Donath et al., 1995, Monat, 2011).

A second challenge pertains to the fact that while a company may objectively identify the exact characteristics of a high-quality lead, information on these characteristics is seldom available before a sales representative has made direct contact with a prospect. Therefore, sellers are often forced to rely on publicly available information that is easily attainable but that does not necessarily reveal information on the prospect's level of interest in the seller's products (Long et al., 2007). This is a significant pitfall, as signals of interest toward a seller's products are considered to be the most important indicators of a prospect's genuine purchase intentions (Bhattacharyya, 2014). The importance of a prospect's interest to the lead qualification process is 
often manifested in the definitions of a lead. For example, Monat (2011, p. 179) defines a lead as "a recorded expressed interest in the company's goods or services."

Content marketing offers new opportunities for B2B sellers to facilitate the lead qualification process. First, when potential buyers are motivated to submit contact information to a website, the seller can design a contact form that requests the information needed to qualify a prospect. Of course, requesting excessive or overly personal questions may result in negative outcomes, as some potential buyers may decide not to leave any information or may contribute inaccurate data (Long et al., 2007). The seller must therefore carefully consider the crucial information needed from potential buyers.

Once the contact information is collected, the seller can send more content (typically via e-mail) related to a prospect's interests. In the content marketing literature, this is referred to as 'lead nurturing' (e.g., Rose \& Pulizzi, 2011). It is defined as a relationship-building approach that supports the prospect's buying process with relevant information until the prospect is deemed ready to be transferred to sales (Michiels, 2008). However, there is very little information available regarding how $\mathrm{B} 2 \mathrm{~B}$ sellers can tailor relevant information to prospects and thereby evaluate which prospects sales representatives should contact. Previous studies show that selecting sales leads from prospects can be facilitated and sales force productivity increased using IT platforms (Ahearne, Hughes, \& Schillewaert, 2007; Eggert \& Serdaroglu, 2011; Moncrief \& Marshall, 2005; Tanner \& Shipp, 2005), and it is thus reasonable to assume that nurturing and qualifying prospects via content marketing would also benefit from the use of IT 
tools such as marketing automation. Ideally, sellers could employ automation to search for signals of interest in the seller's products.

\subsubsection{From leads to deals}

Leads are qualified prospects who are contacted by sales representatives (D'Haen \& Van den Poel, 2013). However, contacting all leads is an ideal rather than a common practice, particularly for the leads generated by marketing departments. Oliva (2006) explains that sales representatives often ignore marketing-generated leads by claiming that they lack sales potential. As a consequence of poor follow-up on marketing-generated leads, it is argued that several companies constantly lose sales-ready buyers (Hasselwander, 2006). According to Sabnis et al. (2013), sales representatives cannot evaluate the objective quality of marketing-generated leads, and thus their follow-up is largely based on their perception of the lead qualification process. Therefore, it is vital that marketers design effective lead qualification methods that are also transparent to sales representatives.

Research indicates that online leads (i.e., leads generated through online sources) lose momentum particularly quickly, suggesting that they require rapid response. In examining 1.25 million online leads received by 29 B2C and 13 B2B companies, Oldroyd, McElheran and Elkington (2011) find that contacting a potential buyer within an hour of receiving a query increases the likelihood of proceeding to sales negotiations with the potential buyer by seven times relative to those sellers that answered queries an hour later and by 60 times relative to those that took over 24 hours to respond. Unfortunately, only $37 \%$ of the companies studied were able to respond to leads within an hour, while the average response time was 42 hours. Oldroyd et al. argue that this slow online lead follow-up stems from an ineffective use of IT tools to 
support sales processes and that companies must employ new tools and processes to meet the demands of the digital age.

Arguably, to best utilize content marketing tactics for lead generation purposes, a company would need to employ marketing automation or other IT tools to allow a quick response to online queries. More specifically, the tool should allow the company to categorize and rank leads so that the sales representatives can respond to the most profitable leads instantly. The literature shows that the effective use of IT can dramatically increase lead management efficiency (Kuruzovich, 2013; Wilson, 2006). One of the most promising avenues for IT use involves integrating web data on customer behavior with the lead qualification process, as web data are known to serve as a strong predictor of profitable customers (D'Haen, Van den Poel, \& Thorleuchter, 2013; Thorleuchter, Van den Poel, \& Prinzie, 2012; Wilson, 2003). Nonetheless, academic research lacks insight into how lead management processes can be improved through the use of the extensive web data available on customer behaviors and the types of IT tools required for this purpose.

\section{Methodology}

\subsection{Research strategy}

A single case study approach was selected as the research strategy of this study. Case study approaches are favored when studies examine real-life instances of contemporary phenomena and when boundaries between phenomena and contexts are not evident (Yin, 2014). Moreover, there is general agreement that a single case can serve as a suitable starting point for in-depth investigation and description (e.g., Easton, 2010; Eisenhardt, 1989; Eisenhardt \& Graebner, 
2007; Johnston, Leach, \& Liu, 1999; Miles, Huberman, \& Saldaña, 2013). Single cases are especially fruitful when exploring new phenomena under rare or extreme circumstances (Eisenhardt \& Graebner, 2007), when phenomena are initially examined in a given field (Eisenhardt, 1991), or when an opportunity for unusual research access becomes available (Yin, 2014). In this study, the 'case' refers to the integration of B2B content marketing and marketing automation usage. The case under investigation is contemporary and rare, as content marketing and marketing automation have not yet been studied in combination, and knowledge on both content marketing and marketing automation remains in its infancy. Moreover, the single case study method is appropriate for the purposes of this study, as the approach focuses on providing a rich description of the case and on advancing theoretical understanding of this new phenomenon.

\subsection{Selection of the case company}

The selection of the case company followed an 'extreme case sampling' strategy, which is a type of purposeful sampling in which cases that are unusual or special some way, such as outstanding successes or notable failures, are selected (Patton, 2002). Identifying a case company that had successfully integrated content marketing with marketing automation tools proved challenging, largely due to low adoption rates of marketing automation software. According to a recent survey by SiriusDecisions, only 16\% of North American B2B companies employ marketing automation technologies (Advertising Age, 2014). By following marketing and industry events, we were able to identify a few B2B companies that had been using both content marketing and marketing automation. Fortunately, one company was willing to provide unusual access to allow detailed examination of the phenomenon. Our selection of this case company was further supported through interviews with experts, two of whom spontaneously mentioned the name of 
the selected company as a progressive example of content marketing and marketing automation usage. The selected case company had already accumulated expertise on combining content marketing with marketing automation for several years, and the company had been invited to present its innovative practices related to the topic in various seminars and events. This evidence gave us a strong impression that the company had given the phenomenon understudy a second thought and had a relatively long-term perspective for critically evaluating its actions. This impression was confirmed in early discussions with representatives from the case company. To conclude, our selection of this particular company as the extreme case context for examining the study phenomenon was well justified.

The selected case company is a large-scale developer and manufacturer of technologically oriented industrial goods and services for environmental and industrial measurement. The company is headquartered in Finland and operates globally, with North America, Europe and Asia serving as its primary market areas. About five years ago, the company made a strategic change toward a market-driven approach to revise its organizational structure and operations in order to better serve its selected customer segments more effectively. From an organizational structure point of view, under the new approach, the sales function was organized around larger business areas, and the marketing function was organized into a single unit serving the needs of the entire corporation (i.e., the company was transformed into a matrix organization). The organizational change clarified the roles of marketing and sales, which enabled tighter cooperation between the functions. Moreover, joining marketing forces entailed the establishment of a new stronger marketing unit with better capabilities to develop the company's operations. 
Currently, the company engages in two major business areas, both of which include several subsegments. One business area focuses primarily on public institutions (e.g., meteorological institutions and airports), and the other serves industrial markets, such as power and life science industries. The characteristics of the business areas and their subsegments vary considerably; accordingly, the complexities of the marketing and sales processes vary across these segments. While certain deals take a matter of days to complete from the initial customer contact to product delivery, others may take up to five years of negotiation to realize. Consequently, the role of content marketing and marketing automation notably varies across segments; however, an evaluation of this varied role is beyond the scope of this study, as we intend to provide a detailed description of the process itself. Moreover, the company has made efforts to conceptualize a marketing and sales process that would satisfy the needs of all purchasing situations, however simple or complex they may be.

\subsection{Data collection}

Data triangulation is essential in case studies (Dubois \& Gibbert, 2010), and hence data were collected from multiple sources. Primary data were obtained through semi-structured interviews. Following Eisenhardt and Graebner's (2007) recommendations, data were collected from knowledgeable company members who hold diverse views on the phenomenon and who supplement one another's stories. Informants were recruited using a snowball-sampling method (Salganik \& Heckathorn, 2004) that began with contacting the Chief Marketing Officer, who suggested the next suitable informant and so forth. This process resulted in five interviews with six individuals who occupy various managerial positions (Table 1). Interviews were conducted with both marketing and sales managers to generate a comprehensive understanding of 
marketing and selling processes and to reveal the sales-related benefits of content marketing and marketing automation. None of the interviews adopted rigidly formed questions and instead employed open-ended questions that focused on predetermined themes: (1) marketing philosophies of the case company, (2) content marketing as a concept and strategy, (3) marketing and sales processes, (4) the use of marketing automation, and (5) the alignment of marketing and sales efforts. The interviewees also offered additional information on these topics throughout the interviews. Study data also included observations of the digital content developed by the case company (i.e., website, blogs, white papers, company profiles of various social media platforms and webinars) to allow a more thorough understanding of the content generated by the company.

Table 1: Study interviewees

\begin{tabular}{|c|c|c|}
\hline Title and role/responsibility & Representative of & $\begin{array}{l}\text { Length of } \\
\text { interview }\end{array}$ \\
\hline $\begin{array}{l}\text { Chief Marketing Officer: } \\
\text { Responsible for leading the entire marketing organization } \\
\text { globally and for reporting marketing results to the CEO. }\end{array}$ & $\begin{array}{l}\text { Case company } \\
\text { (Marketing) }\end{array}$ & $46 \mathrm{~min}$ \\
\hline $\begin{array}{l}\text { Senior Digital Marketing Manager: } \\
\text { Leads a corporate-wide digital marketing team responsible for } \\
\text { the implementation of digital marketing activities, content } \\
\text { management and marketing automation usage. }\end{array}$ & $\begin{array}{l}\text { Case company } \\
\text { (Marketing) }\end{array}$ & $\begin{array}{l}\mathbf{7 8} \text { min } \\
\text { (together with } \\
\text { Digital } \\
\text { Marketing } \\
\text { Specialist A) }\end{array}$ \\
\hline $\begin{array}{l}\text { Digital Marketing Specialist A: } \\
\text { Works as part of the digital marketing team (led by Senior } \\
\text { Digital Marketing Manager). Specializes in the technical } \\
\text { implementation of content marketing through marketing } \\
\text { automation. }\end{array}$ & $\begin{array}{l}\text { Case company } \\
\text { (Marketing) }\end{array}$ & $\begin{array}{l}\mathbf{7 8} \text { min } \\
\text { (together with } \\
\text { Senior Digital } \\
\text { Marketing } \\
\text { Manager) }\end{array}$ \\
\hline $\begin{array}{l}\text { Digital Marketing Specialist B: } \\
\text { Works in the digital marketing team (led by Senior Digital } \\
\text { Marketing Manager). Specializes in marketing analytics and in } \\
\text { the development of marketing activities through the exploitation } \\
\text { of digital data. }\end{array}$ & $\begin{array}{l}\text { Case company } \\
\text { (Marketing) }\end{array}$ & $62 \mathrm{~min}$ \\
\hline $\begin{array}{l}\text { Sales Director: } \\
\text { Leads the sales organization responsible for sales in North and } \\
\text { South America. }\end{array}$ & $\begin{array}{l}\text { Case company } \\
\text { (Sales) }\end{array}$ & $47 \mathrm{~min}$ \\
\hline $\begin{array}{l}\text { Sales Manager: } \\
\text { Leads the sales team responsible for sales in domestic and }\end{array}$ & $\begin{array}{l}\text { Case company } \\
\text { (Sales) }\end{array}$ & $61 \mathrm{~min}$ \\
\hline
\end{tabular}


selected foreign markets.

\section{Managing Director: \\ Leading expert in a company that focuses on marketing automation from a technical perspective.}

\section{CEO:}

Leading expert in a company that focuses on inbound marketing, marketing automation and content marketing in the B2B sector.

\section{Expert company A 102 min}

Expert company B 56 min

\section{CEO:}

Leading expert in a company that focuses on data-driven content marketing.

\section{Expert company C 57 min}

To obtain an external perspective and improve our understanding of the case, three interviews were conducted with $\mathrm{B} 2 \mathrm{~B}$ content marketing and marketing automation experts who were not related to the case company. These interviews helped us to focus on essential issues of the case and to adopt a broader perspective on the phenomenon under investigation. These interviews were also conducted to increase the external validity of the study results, as several critical themes raised by the experts were identified in the study data. In addition to conducting these interviews, we familiarized ourselves with the marketing automation platform (Eloqua) employed by the case company by participating in a technology provider presentation (performed by expert company A) delivered specifically for the purposes of this research. Data were collected until we felt confident that we understood the phenomenon comprehensively and were able to coherently describe the case based on the context of the selected company.

\subsection{Data analysis}

All study data were documented and appropriately stored in a case study database. Interviews were recorded and transcribed verbatim, and we made detailed notes on digital content observations and on the marketing automation platform presentation. Raw data were carefully reviewed several times by two researchers before the analysis was conducted. Notes on the data 
review process were made to support the analysis. The actual analysis was conducted over a three-step thematization procedure that involved data condensation, data display, and conclusion drawing/verification (Miles et al., 2013). Data condensation involved descriptive coding into relevant categories (such as content marketing, marketing automation, and marketing and sales alignment) to eliminate data deemed irrelevant to the case. During the data display phase, the data were organized by using the guiding framework of the study (i.e., sales funnel), ultimately resulting in the marketing and sales funnel concept presented in the results section of this paper. To increase the reliability of the results, the second researcher reviewed the interpretations made by the first researcher during various phases of the analysis. In the data display phase, the second researcher agreed on $88.2 \%$ of the categorization decisions of the first researcher. When interpretations conflicted, the researchers reanalyzed the data together and reached a joint agreement. Subsequently, a detailed description of the case was recorded. Finally, the findings were reviewed and verified by the case company to further increase the validity of the results.

\section{Findings}

Along with the case company's strategic change toward a market-driven approach to operations, the marketing department adopted a new marketing philosophy called "data-driven content marketing." The fundamental premise of the new philosophy was to create and deliver compelling, relevant and valuable content based on individual customer needs; this philosophy was primarily aimed at generating high-quality sales leads. Personalizing content to individual customer needs proved to be a challenge that could only be overcome by combining content marketing approaches with IT tools. For this purpose, the company acquired marketing 
automation software to enable its marketers to target customers "with the right content at the right time."

Today, the case company is more than satisfied with the outcomes achieved. First, the efficiency of the marketing and sales organizations has significantly improved as a result of these automated processes. A large proportion of customer communications and content delivery actions are automated, and any sales leads generated are prequalified through the system so that the sales organization can allocate more resources to actual sales than to assessing lead quality. Second, the volume and quality of sales leads generated through marketing efforts has improved considerably. Third, marketing input contributions to sales outputs have become more transparent, and the marketing department has shifted from serving as a tactical support entity to assuming a strategic decision-making unit function.

'Before the strategic transformation, we had shifts for fixing the copying machine at the office, and I'm not kidding. It's true. Marketing used to be a reactive support function for sales. Our task was to make brochures and events when sales required us to do so. Today, we do things proactively. We focus on designing great content, measuring performance and optimizing marketing tactics continuously.' (Chief Marketing Officer)

Improvements in the stature of marketing are also evidenced by the fact that there is a marketing presence in all business segment management groups, and the director of marketing reports directly to the $\mathrm{CEO}$ of the corporation. All of the marketing interviewees found that the increase in their prestige had been radical in recent years, and they are now highly appreciated by the 
executive board and by other business departments. This view was also expressed by the sales department interviewees.

'Frankly, I have never seen or heard of a better performing marketing unit than ours, no matter who I discuss this with from other companies. Our marketing department generates sales-ready leads for us, and all we have to do is to give them a call. Honestly, I have a long experience of B2B selling, and there are not many companies where the sales department gets such great service. Marketing is truly one of the major keys to our success.' (Sales Manager)

\subsection{Content creation and delivery}

Content marketing, as defined by the interviewees, refers to processes of creating and delivering content (i.e., text messages, pictures, videos, animations) to target customers in ways that add value and engages them in relationships with the company. While the interviewees find that content can take nondigital forms, the case organization focuses heavily on producing digital content of various types: webinars, white papers, newsletters, digital brochures, blog texts, social media posts, infographics, pictures and videos.

The case organization considers generating high-quality content to be an ongoing learning process that involves a continuous examination of content that engages target audiences. While definitions of high-quality content are rather subjective, particular key features characterizing such content were noted repeatedly by interviewees. First, the content design must be informed by target customers' needs. The interviewees noted that companies too often generate content that engages a broad audience but that fails to speak to real customers. A related key element of 
high-quality content is that it creates value for customers rather than merely promoting company products and services. The case company has learned that good content never focuses on products but instead focuses on helping customers to solve their problems and on offering advice on issues customers may feel unsure about. Content produced by the case organization often does not mention the company or its products, but instead focuses purely on a given topic that the company offers expertise in.

'Recently, we designed a series of webinars on how to benefit from this new type of radar technology that was highly successful. Experts around the world came to watch them, returned to watch them again and shared them in social media. You could see that the markets were inquisitive about this topic. When we used some more general topics, the interest was rather low. Understanding the target group's needs is everything when speaking of the absolute effectiveness of content marketing.' (Senior Digital Marketing Manager)

Identifying valuable and relevant content requires a company to be aware of the informational needs of target customers, and this is realized through active listening. In practice, listening is performed by collecting customer feedback and by social media monitoring. In addition to listening to customer interests, a company must also identify and disseminate organizational knowledge to fulfill customer information needs. The case company has made an effort to overcome this challenge by treating content creation as a joint process and combining expertise from different parts of the organization. While marketers coordinate the process, content subject matter is determined by top engineers and subject specialists. Marketers typically interview 
several specialists on a certain customer-relevant topic and then create actual content on their behalf or in collaboration. Part of this process involves considering how interview data may be exploited to generate content of various formats.

'The fundamental idea is that when we create new content, we consider which parts of that content entity is suitable for a white paper, webinar, social media posts, face-to-face selling situations and various events. It is a learning process to be able to adapt the content to the different media so that it works effectively. For example, we have realized that social media posts must be much more entertaining compared to the content delivered through other media.' (Chief Marketing Officer)

Most of the content developed by the case organization is found on the firm's corporate website, while other channels (e.g., search engines, social media platforms, e-mail, advertising media (both online and offline)) are primarily used to promote content and direct target customers (i.e., suspects) to the company website. For example, the company may promote content published on its corporate website via social media posts that include links to webpages where visitors can find more information on a given topic. To access content, the visitor must log in or leave contact information that activates the marketing automation software and initiates the customer's journey through the marketing and sales funnel.

\subsection{The role of content marketing and automation in the marketing and sales funnel}

The acquisition of marketing automation software has been a crucial prerequisite for the company's content marketing strategy, as it has enabled the case company to collect actionable data of potential and existing customers that can be used to deliver timely content for their 
individual needs. Furthermore, the automation software is an effective tool for systematically managing incoming leads at different phases of their purchasing processes. In addition to adopting marketing automation, the case company's decision to treat marketing and sales as integrated elements of the sales process has been equally important. The case company has similarly made efforts to develop a joint marketing and sales funnel (Figure 2).

'Recently, we have come to realize that it is not just a sales funnel but actually a joint marketing and sales funnel, including several phases. Our vision of how the contacts move in the funnel has also developed along the way. We still use the term 'sales funnel' quite often, but we have moved toward the term 'marketing and sales funnel.' (Digital Marketing Specialist B) 


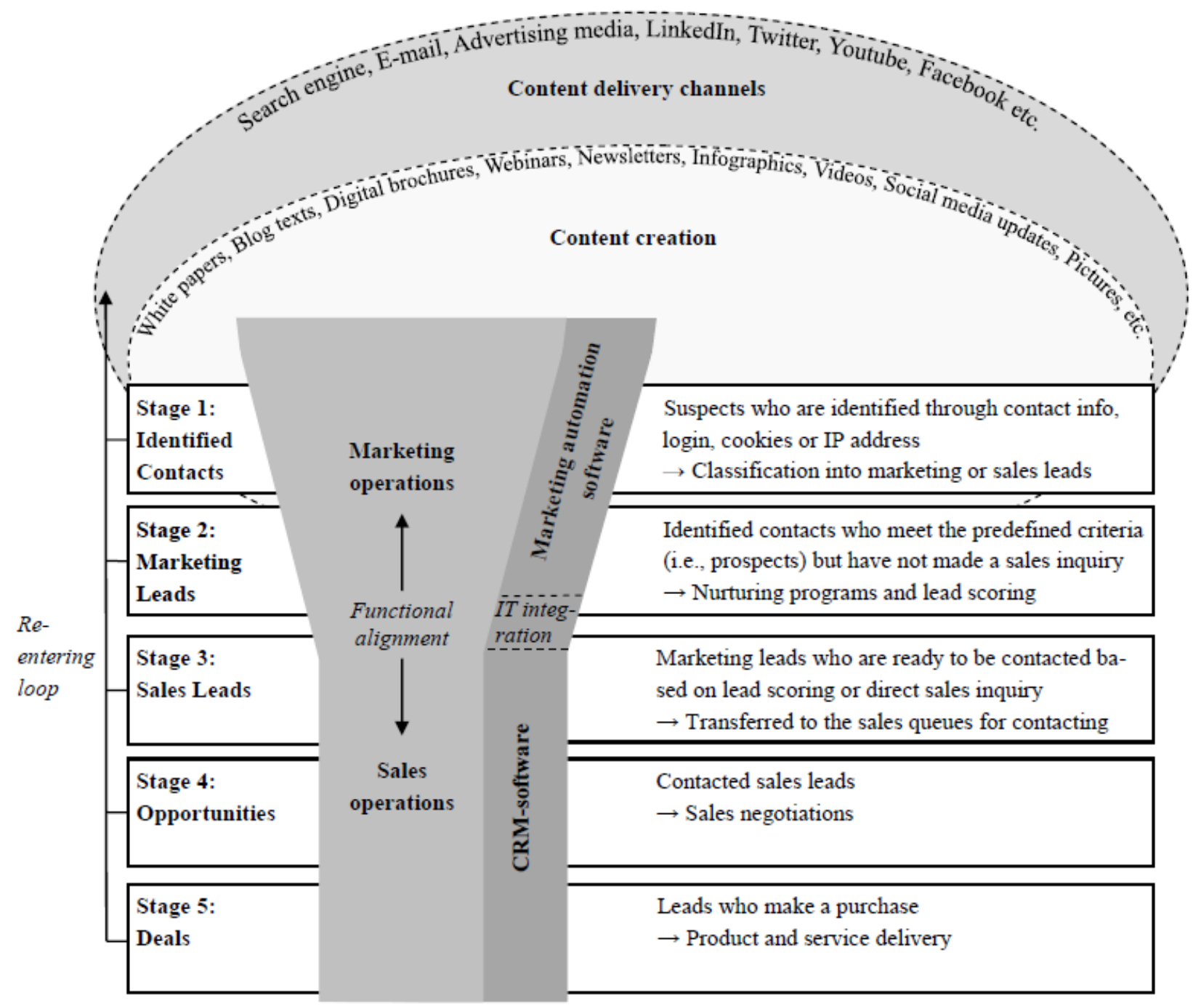

Figure 2: Marketing and sales funnel of the case company

\subsubsection{Stage 1 - Identifying and classifying contacts}

Entering the first stage (i.e., identified contact) of the marketing and sales funnel requires a suspect to be identified by the case company. The suspect is identified upon leaving contact information on the corporate website (or, e.g., at trade shows) as part of a sales inquiry, contact request or digital content access. In addition, existing customers who visit the website are automatically identified by the marketing automation software through an IP address, cookies, an e-mail address or a website login. 
'With regards to new customer acquisition, the first touch point typically occurs online; a customer is somehow attracted to our website and navigates to a webpage where he or she finds interesting content. To get access to that content, the person needs to leave contact information. Thereafter, the automation software follows the person's online behavior over time via an e-mail address, cookies and an IP address.' (Digital Marketing Specialist B)

Technically speaking, the software matches the contact data with the customer database records ${ }^{1}$ to determine whether information on a given individual already exists. The system in turn filters out unqualified contacts that include obvious misinformation or incomplete information.

'We have built a filtering process into the automation software to ensure that the contact data acquired is valid. The filtering process is activated every time we receive new contact data or when existing contact data is updated. We do not want those contacts that lack vital pieces of data or include incorrect data to proceed in the funnel, and that is what the filtering is designed to do.' (Digital Marketing Specialist A)

Information on identified contacts is automatically stored in the customer database, and marketing automation software then categorizes the contacts as marketing or sales leads. The difference between marketing and sales leads is determined as follows:

\footnotetext{
${ }^{1}$ The customer database refers to a contact database of both potential and existing customers whose contact information has been acquired. The customer database is stored in the customer relationship management software and is synchronized with the marketing automation software.
} 
'Marketing leads are identified contacts, so we know who they are, and we have some sort of behavioral data for them but no clear signals of purchase intention. So, based on that data, we can start nurturing these contacts to find out more about their interests to be able to provide more relevant content for their needs and push them closer to the purchase decision. On the other hand, sales leads are those contacts that request a quotation or whose behavior shows clear indications of a purchase intention.' (Digital Marketing Specialist A)

\subsubsection{Stage 2- Nurturing and scoring marketing leads}

By nurturing, the study participants refer to processes through which marketers strive to transform marketing leads into sales leads. This involves attracting, educating and engaging marketing leads through the delivery of meaningful and timely content and thereby encouraging a potential customer to make a purchase decision. Content delivered to a prospect is personalized on the basis of profile information (e.g., company, industry, title) and online behaviors; the online behaviors of the prospect are tracked by the case company from the moment the marketing lead first identifies him or herself by leaving contact information.

'The key to nurturing is personalization in communications. That includes some very simple things, such as greeting the contact by name and using the local language. We can also use the contact's title and industry information to predict what kinds of contents he or she is likely to be interested in. But what is really growing in importance is behavioral personalization. So, we can deliver relevant content to our contacts based on what they do on our website.' (Digital Marketing Specialist B) 
Nurturing is an iterative process wherein marketing leads are targeted with personalized "nurturing campaigns," and in return, marketers learn more about the prospects. For example, a marketing lead who has recently downloaded a white paper on a certain topic is sent an automated email that asks whether the prospect would like to learn more on related topics. If the prospect clicks on one of the links included in the email, he or she is directed to the website where the content is located. Automation software then tracks the prospect's navigation path, generating a more comprehensive picture of the issues that the specific prospect is truly interested in. This information is used to connect prospects with even more specifically targeted content. This process may be repeated numerous times, until the automation generates a clear image of the products and solutions the prospect is searching for. At this point, the prospect is respectfully asked whether he or she would like to be contacted by the sales team. If the answer is yes, the marketing lead becomes a sales lead and is thereafter managed by the sales department.

'In our case, nurturing means that we start to warm up the marketing lead by providing content relevant to the lead's interests. The goal is to learn more about the contact and ultimately guide the contact further in the funnel toward a purchase decision. In the early phase of nurturing, we typically approach the contact at a more general level and deliver content on broader themes. Once we get a better understanding of the lead's needs, we can target the lead with more specific content and solutions. In an ideal situation, the nurturing reaches the point where the lead makes a contact request, which is again transferred to sales. And I can tell you, we receive loads of online sales inquiries as a result of nurturing.' (Digital Marketing Specialist B) 
Even the most apparently interested prospects may not contact the sales team. For this reason, marketers use the marketing automation software's lead scoring system to determine which marketing leads should be transferred to the sales department. As with the content personalization criteria used for nurturing purposes, lead scoring is based on a prospect's profile information and recent online behaviors. Prospect profiles are scored from A to D (A being the best) depending on how well the prospect matches the ideal customer profile (e.g., certain industries and market areas) of the case company. Online behaviors are accordingly scored from 1 to 4 ( 1 being the best) based on how actively the prospect has consumed content and visited the company website over a certain period of time.

'Together with the sales organization, we have determined score weights for marketing leads based on the company that the contact represents and his or her decision authority, geographic location, online behaviors and so on. That way, the automation scores the marketing leads. The leads that exceed a certain score limit are transferred to the CRM system, and sales will take care of them after that.' (Chief Marketing Officer)

The total score that a marketing lead can achieve varies on a scale of A1 to D4. When a marketing lead surpasses a predefined threshold (e.g., B2), he or she is then managed by the sales department. The actual threshold varies across business segments and market regions and is determined by the marketing and sales managers of a given business segment. Moreover, the lead score is not a static rating because a prospect's activity level varies over time, and various other factors affect score weights. For instance, existing customers are given higher ratings 
because they are considered to be more likely to make a purchase, and certain behavioral patterns such as product views are scored higher than views of more generic webpages (e.g., the "about us" page). While both profile information and behaviors affect scores, it is typically behaviors that eventually transform marketing leads into sales leads, as behaviors are considered to offer a stronger indication of the prospect's purchase intention. That said, the time that it takes for a marketing lead to become a sales lead can vary greatly. In some cases, the scoring threshold is set so that all A-level marketing leads are directly transferred to the sales department, and these leads thus skip the marketing lead phase without any nurturing.

'For example, D4-level leads are never transferred to sales because they are simply not the kind of leads we want our sales teams to spend time on. At the moment, marketing leads that are at least on level 2 regarding online behavior may become sales leads, but that requires the marketing automation system to have all of the critical business information on the lead so that the sales representatives can succeed when they contact the lead.' (Senior Digital Marketing Manager)

It is noteworthy that a large proportion of marketing leads are existing customers. Existing customers are particularly suited to nurturing tactics, as the case organization already knows much more about them than about new marketing leads, and their data are enriched with their purchase history. While existing customers may be inactive long after a purchase is made, their contact details (e.g., e-mail address and IP address) are stored in the customer database, and the marketing automation software can detect when they become active again. When this occurs, the 
customer re-enters the funnel as a marketing lead and is targeted with new content based on his or her online behaviors.

'Besides data on online behaviors, we can also exploit the purchase history of our existing customers for automated marketing communications. Among other things, the purchase history can be used for designing an after-sales campaign that is automatically triggered six months after a purchase of a given product. For example, an after-sales campaign may educate a customer about how important it is to overhaul the product purchased and prompt the customer to order maintenance service.' (Senior Digital Marketing Manager)

\subsubsection{Stage 3-Contacting sales leads}

Qualified sales leads are automatically transferred to CRM and distributed to 'lead queues' that assign incoming leads to appropriate sales teams. Lead queues created by the case organization are categorized by geographic location and business segment. Every sales team is essentially responsible for at least one lead queue, and team members are expected to address each lead as soon as it enters the queue.

'The marketing automation system transfers leads to our CRM system, where they are divided into lead queues. The lead queues differ from each other on the basis of geographic location and business area, and certain sales teams are responsible for certain lead queues. So, the sales representatives responsible for a certain queue are required to review and contact the incoming leads. To ensure that we do not ignore any leads and react fast enough, we also get e-mail alerts of new incoming leads.' (Sales Manager) 
Sales inquiries are directly responded to with quotations, but leads subjected to lead scoring must be reviewed before contact is made regarding content and products of interest. Once a lead has been contacted, he or she may be converted to a deal and is therefore referred to as an 'opportunity.'

\subsubsection{Stages 4 and 5 - Closing the deals and beyond}

During the opportunity phase, the case company begins negotiations with a lead to close a deal. In minor purchase cases, no actual negotiations are made, and an opportunity may simply accept or reject a deal. In more significant cases, negotiations may continue over several years, and sales prices may change over this period. Once a deal is won or lost, this information is recorded in the CRM system. In an ideal case, the case organization can review an entire marketing and sales process from the first marketing campaign in which contact information was acquired through all phases of the customer's purchase process.

Finally, the customer's path in the marketing and sales funnel is not always as straightforward as described, but a contact can move back and forth in the funnel over time. The strength of marketing automation is that although a deal may be lost at any phase of the funnel, the customer information remains stored in the database and the customer may re-enter one of the previous phases in the funnel.

'If the opportunity is lost, OK, it's lost; we try to learn from it, but then the contact is still put back into nurturing campaigns with the marketing program. So we don't let them go. We put them into the marketing pool and then try to nurture them to get future potential business.' (Sales Director) 


\subsection{Prerequisites of success and remaining challenges}

Successfully implementing content marketing based on marketing automation does not occur overnight. The interviewees elaborated on the prerequisites for success as well as the future challenges that undermine the realization of the ideal marketing and sales funnel described above. Several interviewees noted that promoting a mindset that supports data-driven content marketing has taken time and effort. Marketers have been required to shift their focus from promotional and product-oriented advertising toward helping buyers with specific content. This was also highlighted in our interviews with experts.

'If you ignore the customer's perspective on it [automation] and go with the same mentality that you had before in marketing, just posting messages, you fail. It does not matter which automation system you choose.' (CEO, Expert Company B)

In addition, planning roles have expanded dramatically, as marketers must set automation system rules that guide content delivery to prospects. In this sense, marketing automation schemes are as clever as their users. A related challenge is that as a company learns more about its customers, smaller segments are identified that must be provided with specific content, and in turn, content creation requirements expand. As resources are always limited, the case company is increasingly considering means of reusing and refining content. Furthermore, as one interviewee (Digital Marketing Specialist B) noted, while content creation and delivery has been the case company's main focus, the firm has not been equally successful in fostering customer dialogue. According to our observations, this is especially the case for social media channels, which are exploited as content delivery channels rather than as forums for customer dialogue. Expert interviewees 
stressed the importance of sales representative social media presence, arguing that participation in social media discussions effectively generates sales leads. This is clearly a missed opportunity for the case company.

Without seamless cooperation between marketing and sales departments, content marketing cannot be successfully integrated with B2B sales processes. Our study data show that seamless cooperation requires not only IT integration between marketing and sales systems (i.e., marketing automation and CRM) but also collaborative planning and functional alignment across departments. This was found to be especially critical to the lead qualification process. When marketing and sales managers determine qualified sales lead criteria together, fewer arguments occur regarding the quality of leads and the appropriate follow-up practices. In the case company, the marketing and sales departments collaborate closely in developing marketing and sales activities, and both parties expressed satisfaction with this arrangement. However, this collaboration is not without friction. The single most problematic issue is that the deals won or lost must be manually recorded in the CRM system by sales representatives. This does not always occur because the company receives numerous minor sales inquiries, and thus deals below a certain monetary value are not recorded in the CRM for efficiency reasons. As an unfortunate consequence, the marketing organization obtains inaccurate data on the quality of the leads generated. This limits opportunities for marketers to develop and optimize marketing activities and to demonstrate total sales contributions. This finding also suggests that the CRM system must be made more user-friendly. 
'Because the volume of sales leads is so great, and the process is not super quick to do, we must bank trade-offs, and so if the dollar value is low, we're not so keen on documenting them. We don't want to document just for the sake of statistics. I want to see that we have logic when we're putting manpower behind things.' (Sales Director)

Another challenge involves further optimizing the marketing lead scoring system, which despite exhibiting significant progress has proven difficult to change. The challenge of creating an effective scoring system was also noted in our interviews with experts.

'Scoring leads is an art... The scoring is dependent on the business and is purely company specific.' (CEO, Expert Company C)

An optimal scoring system should function as a filter that transmits only those leads to sales that are likely to be won, but this remains a developing project in the case company. A few interviewees considered the existing scoring system to be imprecise, as too many unqualified leads are entered into CRM sales lead queues. Consequently, the sales department does not have time to contact all leads and must occasionally make arbitrary evaluations of their relevance. Sales representatives typically prefer leads that appear easy to convert into deals, and those that require a proactive selling approach are often disregarded or contacted late. When lead scoring rules are more rigid, some valuable leads are filtered out by the system, and thus the optimal balance is yet to be achieved. 


\section{Discussion}

The study findings offer three important theoretical contributions. First, this study advances knowledge with regard to organizational processes that foster the creation and delivery of valuable and timely content based on customer needs. The study findings support evidence proposing that content must target customers' needs and solve their problems rather than promoting company products (Davis, 2012; Handley \& Chapman, 2011; Wuebben, 2011). The findings extend this line of reasoning by showing that in addition to actively listening to customer needs, companies can facilitate content creation by promoting collaboration between marketers and subject specialists. This approach may solve the challenges previously identified by $\mathrm{B} 2 \mathrm{~B}$ companies regarding recruiting and engaging subject experts who also serve as competent developers of high-quality content (Holliman \& Rowley, 2014). In regards to delivering timely content, the present study is one of the first to illustrate how IT tools can be harnessed for behavioral targeting so that potential buyers are targeted with specific content based on their recent online behaviors. This approach may overcome B2B firms' challenges in identifying where customers are in their buying cycle and in tailoring messages accordingly (Holliman \& Rowley, 2014).

Second, this study is the first to demonstrate how content marketing strategies can be integrated with selling processes through the use of marketing automation in a way that creates business benefits. Although the phenomenon understudy was investigated in a B2B context, the same principles of combining content marketing and marketing automation presumably apply to a B2C context, especially in terms of behavioral targeting and content personalization. However, the empirical framework (i.e., the marketing and sales funnel) is constrained to industries 
characterized by high-involvement product categories and relatively long-lasting purchase decision cycles (e.g., the car industry). In line with Long et al. (2007) and Holliman and Rowley (2014), content marketing serves as an effective means of attracting suspects who are motivated to identify themselves. Persuading suspects to engage in inbound tactics is becoming increasingly important, as B2B buyers typically assume a more active role in the early phases of their purchasing processes (Adamson et al., 2012; Wiersema, 2013). The study also showed that integrating content marketing and marketing automation efforts can generate high-quality sales leads and increase efficiency levels by overcoming a cumbersome selection process for prospects (see, e.g., Moncrief \& Marshall, 2005; Trailer \& Dickie, 2006) through automated classification. Moreover, behavioral tracking of marketing automation expedites the lead qualification process by signaling prospect interest in particular products, which is often considered to be the most important element of genuine purchase intentions (Bhattacharyya, 2014; Monat, 2011). This finding corroborates evidence that lead qualification can be supported by web data (D'Haen et al., 2013; Thorleuchter et al., 2012) and through the use of IT tools (Ahearne et al., 2007; Eggert $\&$ Serdaroglu, 2011).

As a third contribution, the study presents a novel illustration of a marketing and sales process wherein marketing and sales efforts are coordinated as two facets of the same funnel (i.e., a marketing and sales funnel). From a technological perspective, the study contributes to ongoing discussions on the isolation of marketing and sales systems (Kotler et al., 2006; Wiersema, 2013) by demonstrating that marketing and sales system integration (i.e., marketing automation and CRM) can significantly improve the efficiency of marketing and sales organizations. Marketing departments can transfer qualified leads to sales departments without requiring manual input, and 
sales departments can thus receive leads more quickly. From a marketing and sales alignment perspective, the study findings show that an integrated marketing and sales funnel increases transparency between marketing and sales departments and fosters closer cooperation between the two factions. This form of integration presents the potential to end the endless 'war' between marketing and sales departments with regards to the quality of sales leads and follow-up (Biemans et al., 2010; Homburg \& Jensen, 2007; Homburg et al., 2008; Kotler et al., 2006; Oliva, 2006; Sabnis et al., 2013). When the marketing and sales funnel is transparent to both parties, marketing and sales representatives can collaboratively determine lead qualification and follow-up criteria.

\subsection{Managerial implications}

From a managerial perspective, extreme case studies of success or failure are often more useful than survey-based results (Johnston et al., 1999). Following this logic, the present case study serves as an extreme case of marketing automation for B2B content marketing and presents a number of managerially relevant implications. First, managers must understand that content marketing and marketing automation tactics are learned over time and require cultural change within the organization. Managers can facilitate this learning process by offering training and suitable leadership that encourages marketers to learn by trial and error. In addition, managers should consider acquiring new talent by recruiting employees that understand the characteristics of the digital age, such as the role of search engines and social media platforms in B2B purchasing processes. Automation adoption also requires expertise in IT and data analytics tools, which is not always found within a company. Overall, managers must know that reaping the benefits of content marketing and marketing automation efforts requires time and monetary investment, and thus patience is necessary. 
Marketing and sales alignment is one area in which managerial intervention is often required. If there is a conflict of interest between the two parties, it is the manager's responsibility to hear both sides and to find a mutually satisfying solution. Integrating marketing and sales systems and developing a joint funnel promotes transparency and cooperation between marketing and sales departments, and thus we highly recommend managers adopt this strategy. Moreover, the integrated marketing and sales funnel expands opportunities for managerial tracking; managers can track the quantity and quality of marketing leads and review how actively sales representatives follow up on leads. This enables managers to determine whether sales figures are a result of poor lead quality or insufficient follow-up practices.

Despite the opportunities presented by managerial tracking tactics, managers should be mindful when evaluating the performance of marketing or sales departments individually. Accusing either department of poor results is likely to result in further conflict. Moreover, as the two functions are tightly linked, outcomes are ultimately dependent on their combined performance. While it is reasonable to set department specific objectives, these must be used for learning and optimization purposes and not for purposes of performance evaluation. In conclusion, we recommend that managers measure marketing and sales performance based on joint metrics to foster cooperation between the two functions. 


\subsection{Evaluating the quality of the study}

Three criteria must be considered in an evaluation of the quality of a descriptive case study design: construct validity, external validity and reliability ${ }^{2}$ (Yin, 2014). First, construct validity refers to 'the extent to which a study investigates what it claims to investigate' (Dubois \& Gibbert, 2010, p. 132). Construct validity was established in this study by using several informants and multiple sources of data (i.e., case organization interviews, digital content observations, expert interviews and a technology provider presentation) to examine the research phenomenon from various angles and thus to achieve data triangulation (e.g., Beverland \& Lindgreen, 2010; Piekkari, Plakoyiannaki \& Welch, 2010). In line with the suggestion by Yin (2014), the study also provided readers with a clear chain of evidence by carefully describing the progression of the study from the study objectives to the final conclusions. Finally, the results were sent to the case organization to verify the validity of the findings and to prevent misunderstandings and factual errors.

External validity in case studies concerns whether a 'domain to which a study's findings can be generalized' can be defined (Yin, 2014, p. 46). The present case study is limited in terms of its statistical generalizability, as in almost all case studies (Dubois \& Gibbert, 2010; Yin, 2014). However, instead of statistical generalizability, the study aims to achieve analytical generalizability, which refers to the extent to which the empirical observations are generalizable to theory—rather than a population (Yin, 2014). The analytical generalizability of our study findings was enhanced through the establishment of a solid theoretical framework (i.e., sales funnel) that guided our inquiry. The findings are largely consistent with the selected theoretical

\footnotetext{
${ }^{2}$ Internal validity concerns whether causal relationships can be established between study variables; it should thus be assessed only in causal and explanatory case studies, not in descriptive case studies (Beverland \& Lindgreen, 2010; Dubois \& Gibbert, 2010; Yin 2014).
} 
framework, and particular care was taken to discuss the development of the empirical framework (i.e., the marketing and sales funnel) based on the theoretical framework in the light of the empirical observations. The transferability of the empirical framework was further supported by interviews with experts, whose perceptions were largely in line with the findings. Nevertheless, as the sales funnel concept has taken various forms in the literature (D'Haen \& Van den Poel, 2013), the exact form of the marketing and sales funnel is likely to vary in other settings. Specifically, while the major principles of the funnel are supported by existing theory and thus presumed to hold across contexts, the number and type of stages may vary. Finally, the study provides a clear justification for the selection of the case study and a detailed description of the case study context. This provided information helps the reader understand the empirical findings in the context of the selected case company and the potential applicability of the findings to other research settings.

Reliability refers to the absence of random error, which can be enhanced in case studies through transparent data collection and analysis processes that allow for the study to be replicated (Batt, 2012; Dubois \& Gibbert, 2010). To meet the reliability requirement, the researchers developed a case study database in which all study data were appropriately stored (Yin, 2014). Moreover, the study provides readers with elaborate documentation describing how the study was framed and conducted. The data gathering methods are clearly reported, and the data analysis is made transparent by describing step-by-step how the analysis process was conducted and how the authors reached agreement in cases of conflicting interpretations in order to draw reliable inferences. 


\subsection{Future research}

This study offers promising avenues for future research. First, as this study examined B2B content marketing based on a lead generation and sales perspective, future studies may examine how marketing automation mechanisms can be harnessed to create and share content for other key objectives of content marketing (e.g., promoting brand awareness and engagement) (Holliman \& Rowley, 2014; Pulizzi \& Handley, 2014). In particular, more research must be performed on the role of social media in $\mathrm{B} 2 \mathrm{~B}$ content marketing and on the extent to which social media activities can be automated using new technologies.

Future research must also make a better use of online behavioral data. Combining online behavioral data with other customer-specific information such as purchasing histories may generate new knowledge on long-term customer relationships and on customer profitability. Studies could also examine how various marketing stimuli and content formats affect the online behaviors of customer profiles.

Finally, as marketing automation increases the transparency of digital touch points through the customer purchase process, researchers may take advantage of this opportunity and examine the role of digital marketing tactics and channels in B2B customer purchasing processes. Such findings would help identify the tactics that work most effectively at various phases of the marketing and sales process. 


\section{References:}

Adamson, B., Dixon, M., \& Toman, N. (2012). The end of solution sales. Harvard Business Review, 90(7-8), 60-68. Advertising age. (2014). Only 16\% of B2B Companies Use Marketing Automation: Study. 27 May 2014. Available at: http://adage.com/article/btob/16-b2b-companies-marketing-automation-study/293410/ [Accessed 16 February 2015]

Ahearne, M., Hughes, D., \& Schillewaert, N. (2007). Why sales reps should welcome information technology: Measuring the impact of CRM-based IT on sales effectiveness. International Journal of Research in Marketing, 24(4), 336-349.

Batt, P. (2012). Measures and measurement: Process and practise. Industrial Marketing Management, 41(3), 379384.

Beverland, M., \& Lindgreen, A. (2010). What makes a good case study? A positivist review of qualitative case research published in Industrial Marketing Management, 1971-2006. Industrial Marketing Management, 39(1), 56-63.

Bhattacharyya, B. S. (2014). Improving inventory demand forecasting by using the sales pipeline : A case study. Journal of Business Forecasting, 33(1), 7-11.

Biemans, W., Brenčič, M., \& Malshe, A. (2010). Marketing-sales interface configurations in B2B firms. Industrial Marketing Management, 39(2), 183-194.

Buttle, F. (2009). Customer relationship management: Concepts and Technologies. (2 ${ }^{\text {nd }}$ ed.) London: Taylor \& Francis.

Chaffey, D., \& Smith, P.R. (2013). Emarketing excellence: Planning and optimizing your digital marketing. (4 ${ }^{\text {th }}$ ed.) London: Taylor \& Francis.

Christodoulides, G. (2009). Branding in the post-internet era. Marketing Theory, 9(1), 141-144.

Cooper, M. J., \& Budd, C. S. (2007). Tying the pieces together: A normative framework for integrating sales and project operations. Industrial Marketing Management, 36(2), 173-182.

D’Haen, J., \& Van den Poel, D. (2013). Model-supported business-to-business prospect prediction based on an iterative customer acquisition framework. Industrial Marketing Management, 42(4), 544-551.

D'Haen, J., Van den Poel, D., \& Thorleuchter, D. (2013). Predicting customer profitability during acquisition: Finding the optimal combination of data source and data mining technique. Expert Systems with Applications, 40(6), 2007-2012.

Dalrymple, D., Cron, W., \& DeCarlo, T. (2004). Sales management. ( $8^{\text {th }}$ ed.) Hoboken, NJ: John Wiley \& Sons.

Davis, A. (2012). Brandscaping: Unleashing the power of partnerships. Cleveland, Ohio: Content Marketing Institute.

Dennis, C., Merrilees, B., Jayawardhena, C., \& Wright, L. T. (2009). E-consumer behaviour. European Journal of Marketing, 43(9/10), 1121-1139.

Donath, B., Crocker, R., Dixon, C., \& Obermayer, J. (1995). Managing sales leads: How to turn every prospect into a customer. Lincolnwood, IL: NTC Business Books

Donath, B. (1999). Quality information leads to quality leads. Marketing News, 33(17), 11.

Dubois, A., \& Gibbert, M. (2010). From complexity to transparency: managing the interplay between theory, method and empirical phenomena in IMM case studies. Industrial Marketing Management, 39(1), $129-136$.

Easton, G. (2010). Critical realism in case study research. Industrial Marketing Management, 39(1), $118-128$.

Eggert, A., \& Serdaroglu, M. (2011). Exploring the impact of sales technology on salesperson performance: A taskbased approach. Journal of Marketing Theory and Practice, 19(2), 169-185.

Eisenhardt, K. (1989). Building theories from case study research. The Academy of Management Review, 14(4), 532550.

Eisenhardt, K., \& Graebner, M. (2007). Theory building from cases: Opportunities and challenges. Academy of Management Journal, 50(1), 25-32.

Eisenhardt, K. (1991). Better stories and better constructs: The case for rigor and comparative logic. Academy of Management Review, 16(3), 620-627.

Fournier, S., \& Avery, J. (2011). The uninvited brand. Business Horizons, 54(3), 193-207.

Greenberg, P. (2010). The impact of CRM 2.0 on customer insight. Journal of Business \& Industrial Marketing, 25(6), 410-419.

Halligan, B., \& Shah, D. (2010). Inbound marketing: Get found using Google, social media, and blogs. Hoboken, NJ: Wiley \& Sons.

Handley, A., \& Chapman, C. (2011). Content rules. Hoboken, NJ: Wiley \& Sons. 
Hasselwander, A. (2006). B2B Marketing Confidential: B2B pipeline management. 18 November 2006. Available at: http://b2bmarketingconfidential.blogspot.fi/2006/11/b2b-pipeline-management.html [Accessed 23 January 2015]

Hennig-Thurau, T., Malthouse, E., Friege, C., Gensler, S., Lobschat, L., Rangaswamy, A., \& Skiera, B. (2010). The impact of new media in consumer relationships. Journal of Service Research, 13(3), 311-330.

Holliman, G., \& Rowley, J. (2014). Business to business digital content marketing: marketers' perceptions of best practice. Journal of Research in Interactive Marketing, 8(4), 269-293.

Homburg, C., \& Jensen, O. (2007). The thought worlds of marketing and sales: Which differences make a difference? Journal of Marketing, 71(July), 124-142.

Homburg, C., Jensen, O., \& Krohmer, H. (2008). Configurations of marketing and sales: A taxonomy. Journal of Marketing, 72(March), 133-154.

Hubspot. (2015). What is marketing automation? Available at: http://www.hubspot.com/marketing-automationinformation [Accessed 15 February 2015]

Järvinen, J., \& Karjaluoto, H. (2015). The use of Web analytics for digital marketing performance measurement. Industrial Marketing Management (in press). Advance online publication. doi:10.1016/j.indmarman.2015.04.009

Johnston, W., Leach, M., \& Liu, A. (1999). Theory testing using case studies in business-to-business research. Industrial Marketing Management, 28(3), 201-213.

Jolson, M., \& Wotruba, T. (1992). Selling and sales management in action: Prospecting: A new look at this old challenge. Journal of Personal Selling and Sales Management, 12(4), 59-66.

Jolson, M. (1988). Qualifying sales leads: The tight and loose approaches. Industrial Marketing Management 17(3), 189-196.

Kantrowitz, A. (2014). The CMO's guide to marketing automation. Advertising Age, 85(17), 24.

Kietzmann, J. H., Hermkens, K., McCarthy, I. P., \& Silvestre, B. S. (2011). Social media? Get serious! Understanding the functional building blocks of social media. Business Horizons, 54(3), 241-251.

Kotler, P., Rackham, N., \& Krishnaswamy, S. (2006). Ending the war between sales and marketing. Harvard Business Review, 84(7/8), 68-78.

Kuruzovich, J. (2013). Sales technologies, sales force management, and online infomediaries. Journal of Personal Selling and Sales Management, 33(2), 211-224.

Long, M., Tellefsen, T., \& Lichtenthal, J. (2007). Internet integration into the industrial selling process: A step-bystep approach. Industrial Marketing Management, 36(5), 676-689.

Marcus, C. (2002). Re-engineering lead management. Research report, Gartner. 7 October 2002. Available at: https://www.gartner.com/doc/372950/reengineering-lead-management [Accessed 16 December 2014]

Lingqvist, O., Plotkin, C., \& Stanley, J. (2015). Do you really understand how your business customers buy? Research article, McKinsey. February 2015. Available at:

http://www.mckinsey.com/Insights/Marketing_Sales/Do_you really understand_how_your_business_custo mers buy?cid=mckgrowth-eml-alt-mkq-mck-oth-1502 [Accessed 23 February 2015]

Michaelidou, N., Siamagka, N., \& Christodoulides, G. (2011). Usage, barriers and measurement of social media marketing: An exploratory investigation of small and medium B2B brands. Industrial Marketing Management, 40(7), 1153-1159.

Michiels, I. (2008). Lead Nurturing: The Secret to Successful Lead Generation. Reseach report, Aberdeen Group. November 2008. Available at: http://www.contentmarketinginstitute.com/wpcontent/uploads/2012/07/Aberdeen-Lead-Nurturing-study.pdf [Accessed 22 February 2015]

Miles, M., Huberman, A., \& Saldaña, J. (2013). Qualitative data analysis: A methods sourcebook. (3 ${ }^{\text {rd }}$ ed.) Thousand Oaks, CA: Sage.

Monat, J. P. (2011). Industrial sales lead conversion modeling. Marketing Intelligence \& Planning, 29(2), 178-194.

Moncrief, W. C., \& Marshall, G. W. (2005). The evolution of the seven steps of selling. Industrial Marketing Management, 34(1), 13-22.

Montgomery, A., \& Smith, M. (2009). Prospects for personalization on the Internet. Journal of Interactive Marketing, 23(2), 130-137.

Montgomery, A., \& Srinivasan, K. (2003). Learning about customers without asking. In: Pal, N., \& Rangaswamy, A. (Eds.), The power of one - Leverage value from personalization technologies (pp. 122-143). Penn State University: eBRC Press.

Oldroyd, J. B., McElheran, K., \& Elkington, D. (2011). The short life of online sales leads. Harvard Business Review, 89(3), 28. 
Oliva, R. A. (2006). The three key linkages: improving the connections between marketing and sales. Journal of Business \& Industrial Marketing, 21(6), 395-398.

Patterson, L. (2007). Marketing and sales alignment for improved effectiveness. Journal of Digital Asset Management, 3(4), 185-189.

Patton, M. (2002). Qualitative Research \& Evaluation Methods. ( $3^{\text {rd }}$ ed.) Thousand Oaks, CA: Sage.

Petty, R., \& Cacioppo, J. (1986). The elaboration likelihood model of persuasion. In Berkowitz, L. (Ed.), Advances in Experimental Social Psychology (vol. 19, pp. 123-205). San Diego, CA: Academic Press.

Phippen, A., Sheppard, L., \& Furnell, S. (2004). A practical evaluation of Web analytics. Internet Research, 14(4), 284-293.

Piekkari, R., Plakoyiannaki, E., \& Welch, C. (2010). “Good” case research in industrial marketing: Insights from research practice. Industrial Marketing Management, 39(1), 109-117.

Pomirleanu, N., Schibrowsky, J. A., Peltier, J., \& Nill, A. (2013). A review of internet marketing research over the past 20 years and future research direction. Journal of Research in Interactive Marketing, 7(3), 166-181.

Pulizzi, J., \& Handley, A. (2014). B2B content marketing: 2015 benchmarks, budgets, and trends - North America. October 2014. Available at: http://contentmarketinginstitute.com/wpcontent/uploads/2014/10/2015_B2B_Research.pdf [Accessed 10 January 2015]

Pulizzi, J. (2011). The rise of storytelling as the new marketing. Public Research Quarterly, 28 (2), 116-123.

Rodriguez, M., Dixon, A. L., \& Peltier, J. W. (2014). A review of the interactive marketing literature in the context of personal selling and sales management. Journal of Research in Interactive Marketing, 8(4), 294-308.

Rose, R., \& Pulizzi, J. (2011). Managing Content Marketing. Cleveland, OH: CMI Books.

Rygielski, C., Wang, J.-C., \& Yen, D. C. (2002). Data mining techniques for customer relationship management. Technology in Society, 24(4), 483-502.

Sabnis, G., Chatterjee, S. C., Grewal, R., \& Lilien, G. L. (2013). The sales lead black hole: On sales reps' follow-up of marketing leads. Journal of Marketing, 77(January), 52-67.

Salganik, M., \& Heckathorn, D. (2004). Sampling and estimation in hidden populations using respondent-driven sampling. Sociological Methodology, 34(1), 193-239.

Singh, S., \& Sonnenburg, S. (2012). Brand performances in social media. Journal of Interactive Marketing, 26(4), 189-197.

Tanner, J. F., \& Shipp, S. (2005). Sales technology within the salesperson's relationships: A research agenda. Industrial Marketing Management, 34(4), 305-312.

Thorleuchter, D., Van den Poel, D., \& Prinzie, A. (2012). Analyzing existing customers' websites to improve the customer acquisition process as well as the profitability prediction in B-to-B marketing. Expert Systems with Applications, 39(3), 2597-2605.

Trailer, B., \& Dickie, J. (2006). Understanding what your sales manager is up against. Harvard Business Review, $84(7 / 8), 48-55$.

Wiersema, F. (2013). The B2B agenda: The current state of B2B marketing and a look ahead. Industrial Marketing Management, 42(4), 470-488.

Wilson, R. D. (2003). Using online databases for developing prioritized sales leads. Journal of Business and Industrial Marketing, 18(4/5), 388-402.

Wilson, R. D. (2006). Developing new business strategies in B2B markets by combining CRM concepts and online databases. Competitiveness Review: An International Business Journal, 16(1), 38-43.

Wilson, R. D. (2010). Using clickstream data to enhance business-to-business web site performance. Journal of Business \& Industrial Marketing, 25(3), 177-187.

Wolk, A., \& Theysohn, S. (2007). Factors influencing website traffic in the paid content market. Journal of Marketing Management, 23(7-8), 769-796.

Wuebben, J. (2011). Content is currency: Developing powerful content for Web and mobile. Boston, MA: Nicholas Brealey.

Yin, R.K. (2014). Case Study Research. Design and Methods. (5 $5^{\text {th }}$ ed.) Thousand Oaks, CA: Sage. 